\title{
Synthesis and Redox Properties of Crowded Triarylphosphines Possessing Ferrocenyl Groups
}

\author{
Katsuhide Sutoh, Shigeru Sasaki, * and Masaaki Yoshifuji \\ Department of Chemistry, Graduate School of Science, Tohoku University, \\ Aoba, Sendai 980-8578, Japan \\ sasaki@mail.tains.tohoku.ac.jp
}

Osteryoung square wave voltammetry. Measured on a BAS CV-50W controller. Conditions: ca. $10^{-4}$ $\mathrm{M}$ in dichloromethane with $0.1 \mathrm{M} \mathrm{n}-\mathrm{Bu}_{4} \mathrm{NClO}_{4}$ as a support electrolyte. Working electrode is glassy carbon, counter electrode is $\mathrm{Pt}$ wire, and reference electrode is $\mathrm{Ag} / 0.01 \mathrm{M} \mathrm{AgNO}_{3}$ in acetonitrile with $0.1 \mathrm{M} n-\mathrm{Bu}_{4} \mathrm{NClO}_{4}\left(E_{1 / 2}(\right.$ Ferrocene/Ferricinium $\left.)=0.18 \mathrm{~V}\right) . \quad \mathrm{T}=293 \mathrm{~K}$. 5b: Step E.: $1 \mathrm{mV}$; S.W. amp.: $40 \mathrm{mV}$; Frequency: $5.0 \mathrm{~Hz}$; Sample per point: 256. 5c: Step E.: $2 \mathrm{mV}$; S.W. amp.: $5 \mathrm{mV}$; Frequency: 5 Hz; Sample per point:16.

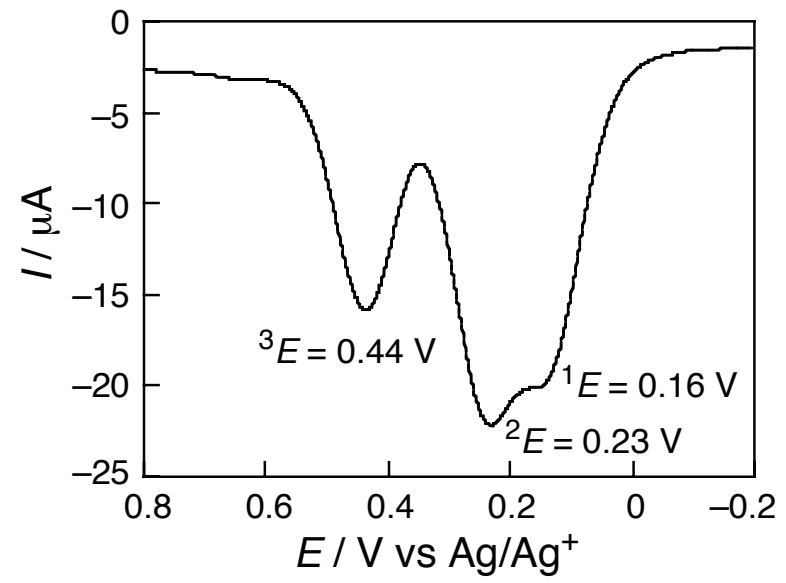

Figure 1. Osteryoung square wave voltammogram of $\mathbf{5 b}$.

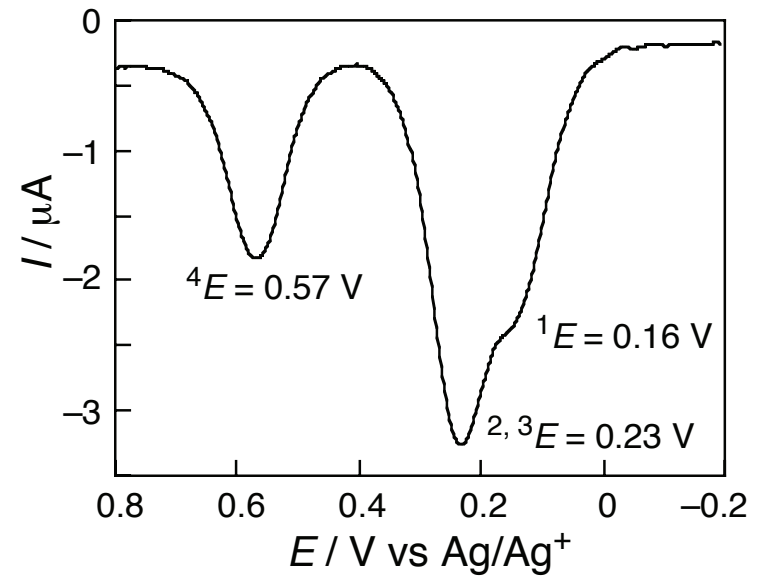

Figure 2. Osteryoung square wave voltammogram of $5 c$. 


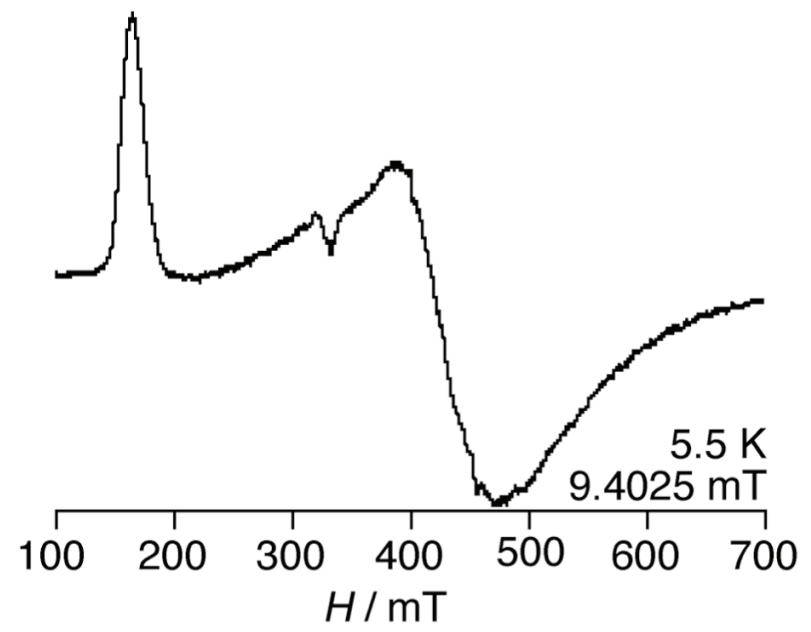

Figure 3. EPR spectra obtained after oxidation of 6 with $\mathrm{AgClO}_{4}$ in dichloromethane at $5.5 \mathrm{~K} . g_{/ /}=4.05$, $g_{\perp}=1.50$. 